\title{
Derrame pleural mielomatoso
}

\section{Sr. Director:}

El mieloma múltiple (MM) es una proliferación monoclonal de células plasmáticas, que afecta principalmente al hueso y médula ósea, aunque también puede producir lesiones extraóseas (1). El tórax puede afectarse en MM por plasmocitomas intra y extramedulares, infiltrados pulmonares, y derrame pleural (2). El derrame pleural se presenta en 6\% de MM (3), y habitualmente es no mielomatoso, en relación a síndrome nefrótico, embolismo pulmonar, insuficiencia cardíaca secundaria a amiloidosis, infiltración y obstrucción linfática mediastínica o segunda neoplasia. El derrame pleural mielomatoso (DPM) se produce por infiltración pleural de células plasmáticas monoclonales, que pueden proceder de lesión ósea o parenquimatosa contigüa, implantación pleural por vía hematógena, o ambos mecanismos. Es muy infrecuente (1\% de MM), publicándose unicamente casos aislados (49). En $80 \%$ de casos de DPM se trata de MM tipo IgA.

Se presenta un caso de DPM tipo IgA, como primera manifestación clínica de MM.

Varón, 72 años, con antecedentes de hipertensión arterial, enfermedad ulcerosa péptica (ulcus duodenal) e hiperplasia benigna de próstata (adenoma). Exfumador de 20-30 cigarrillos/día desde hacía 10 años. En tratamiento con lacidipino (4 $\mathrm{mg}$ /día), pantoprazol (40 mg/día) y terazosina (5 mg/día). Presentaba disnea progresiva de 1 mes de evolución, tos con expectoración amarillenta y febrícula $\left(37,5^{\circ} \mathrm{C}\right)$, así como dolor lumbar intenso. En exploración física destacaba auscultación pulmonar con hipofonesis global, roncus y sibilancias dispersas y semiología de derrame pleural derecho. En analítica destacaba, Hemograma: anemia (hemoglobina $8,7 \mathrm{~g} / \mathrm{dl}$ ) normocrómica normocíti$\mathrm{ca}$, con series blanca y plaquetaria normales. Gasometría arterial basal con insuficiencia respiratoria global $\left(\mathrm{pH} 7,39 ; \mathrm{pO}_{2} 54\right.$ mmHg; $\mathrm{pCO}_{2} 46 \mathrm{mmHg}, \mathrm{HCO}_{3} 27 \mathrm{mmol} / \mathrm{l} ; \mathrm{satO} 285 \%$ ). Bioquímica sérica, coagulación, y hormonas tiroideas (T4libre y TSH) normales. En radiología de tórax: derrame pleural derecho significativo y en tomografía computarizada (TC) toraco-abdominal: derrame pleural bilateral de predominio derecho con atelectasia 


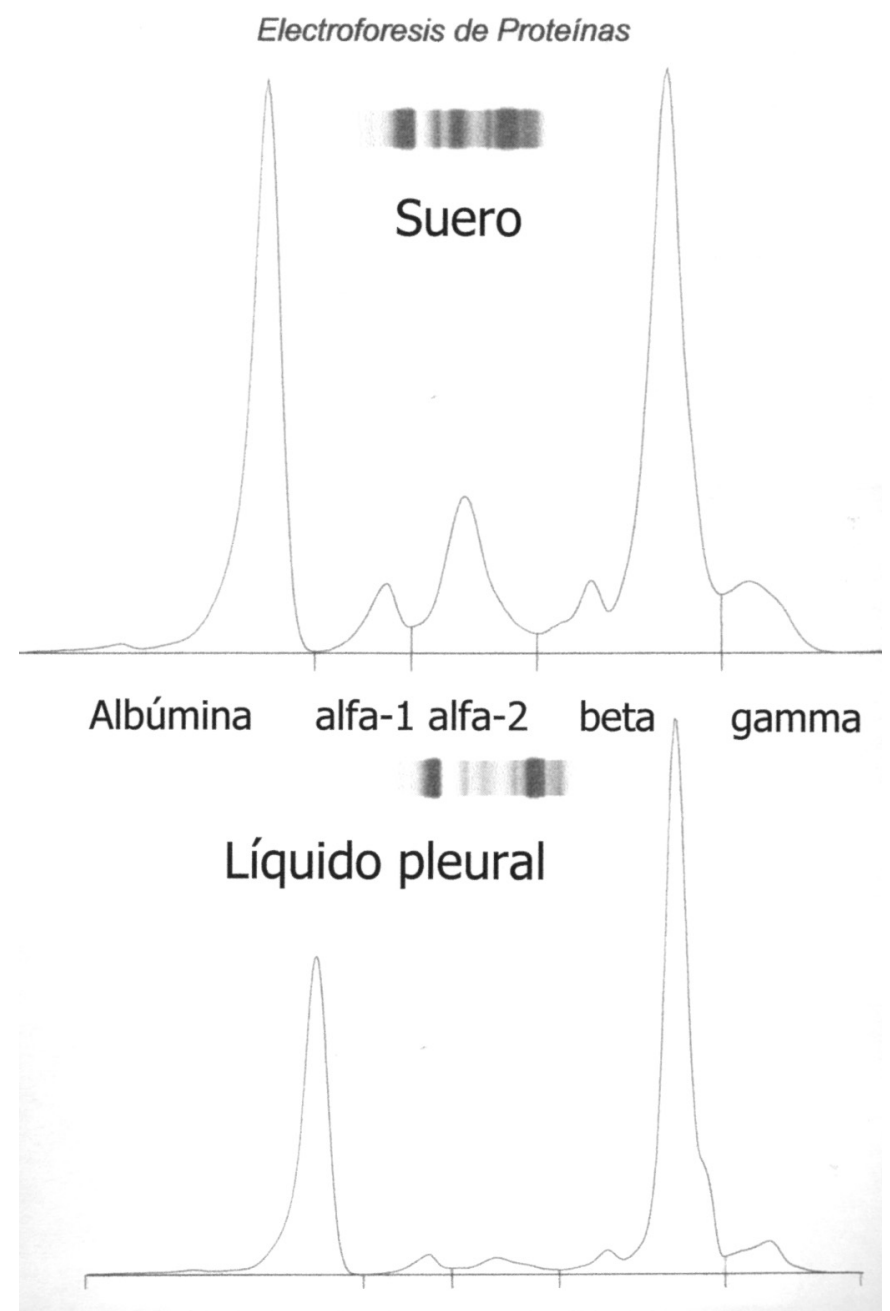

Fig. 1.

de lóbulo inferior derecho y múltiples lesiones líticas en parrilla costal, cuerpos vertebrales y pelvis. La toracocentesis mostró un exudado serohemático, con 2.680 leucocitos $/ \mathrm{mm}^{3}, 3.510$ hematíes $/ \mathrm{mm}^{3}$, pH 7,42; glucosa $126 \mathrm{mg} / \mathrm{dl}$, proteinas 5,38 g/dl, LDH $426 \mathrm{U} / \mathrm{l}$; ADA 49 U/l; citología con abundantes células atípicas, de aspecto plasmocitoide, compatible con infiltración por mieloma. En proteinograma en suero y líquido pleural (Fig. 1) se detectó pico $\mathrm{M}$ en zona beta-gamma, correspondiente en inmunoelectroforesis a cadenas ligeras lambda (en suero: $2.750 \mathrm{mg} / \mathrm{dl}$; rango normal 313-723 mg/dl) de IgA (en suero: $2.870 \mathrm{mg} / \mathrm{dl}$; rango normal $82-453 \mathrm{mg} / \mathrm{dl})$. En inmunoelectroforesis en orina se detectó proteinuria de Bence-Jones tipo cadenas ligeras lambda. El aspirado de médula ósea fue compatible con mieloma múltiple, con $36 \%$ de células plasmáticas sobre la celularidad total. Se inició quimioterapia con melfalan-prednisona confirmándose con bortezomib y dexametasona, ante la persistencia de derrame pleural derecho masivo, que precisó varios ingresos con toracocentesis evacuadoras, se realizó pleurodesis con bleomicina y posteriormente doxicilina, que fueron ineficaces. Se propuso la realización de pleurodesis con talco mediante toracoscopia, a realizar bajo anestesia local por el compromiso respiratorio severo del paciente para anestesia general, siendo rechazada por éste, procediéndose a la colocación de tubo torácico permanente, con drenaje intermitente de líquido pleural $(1.000 \mathrm{ml}$ en primeros 30 días). El paciente falleció a los 9 meses del diagnóstico.

El DPM se diagnostica al detectar células plasmáticas atípicas y/o paraproteína anómala en electroforesis e inmunoelectrofore- sis de líquido pleural, o infiltración mielomatosa pleural en biopsia o necropsia. La infiltración de serosas (pleura, peritoneo) en MM indica mayor agresividad y es un factor de mal pronóstico, con una supervivencia media inferior a 4-6 meses (10), aunque hay casos descritos de supervivencias mayores (7), incluso superior a los 3 años (4). El DPM suele producirse en la fase tardía del MM, aunque hay casos publicados (5,7-9), como el aquí presentado, que son la manifestación inicial de la enfermedad, indicando quizás una mayor agresividad del MM. Respecto a los niveles de ADA en DPM, pueden ser normales o elevados.

\section{E. Crespo Valadés, M. J. Espinosa de los Monteros Garde ${ }^{1}$}

Servicios de Medicina Interna $y^{\prime}$ Neumología. Hospital Virgen de la Salud. Toledo

1. Kyle RA. Multiple myeloma. Review of 869 cases. Mayo Clin Proc 1975; 50: 29-40.

2. Kintzer JS, Rosenow EC, Kyle RA. Thoracic and pulmonary abnormalities in multiple myeloma. Arch Intern Med 1978; 138: 727-30.

3. Alexandrakis MG, Passam FH, Kyriakou DS, Bouros D. Pleural effusions in hematologic malignancies. Chest 2004; 125: 1546-1555.

4. Vidaller A, Pac MV, Moga I, Badrinas F, Ariza X, Millá F, et al. Derrame pleural en el mieloma múltiple. A propósito de 2 observaciones. An Med Interna (Madrid) 1984; 1: 287-91,

5. García AA, Calpe JL, Carbonell MC, Vilar A. Derrame pleural mielomatoso como primera manifestación de un mieloma múltiple. Sangre (Barc) 1989; 34: 520-1,

6. Rodríguez JN, Pereira A, Martínez JC, Conde J, Pujol E. Pleural effusion in multiple myeloma. Chest 1994, 105: 622-4,

7. Acín P, Woessner S, Solé F, Pedro C. Derrame pleural mielomatoso como forma de presentación de un mieloma múltiple. Med Clin (Barc) 1996; 106: 799,

8. García Montesinos R, Avisbal Portillo N, Velasco Garrido JL, Rueda Rios C, Bujalance Zafra J, Ramírez Ramírez G. Derrame pleural como forma de presentación del mieloma múltiple. Rev Clin Esp 2001; 201: 424-5,

9. Nieto ML, Soler JJ, Jarque I. Derrame pleural como primera manifestación del mieloma múltiple. Arch Bronconeumol 1997; 33: 70-1,

10. Meoli A, Willsie S, Fiorella R. Mielomatous pleural effusion. South Med J 1997; 90: 65-8, 